\section{№ 82}

\section{Diset}

Diretoria de Estudos e Políticas Setoriais de Inovação e Infraestrutura

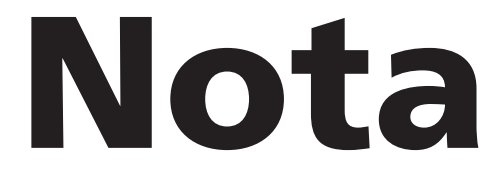

Técnica

PREVISÃO DE ARRECADAÇÃO DE RECURSOS DO FUNDO NACIONAL DE DESENVOLVIMENTO CIENTÍFICO E TECNOLÓGICO (FNDCT) PARA O PERÍODO 2021-2024, SEGUNDO NOVAS DETERMINAÇÕES LEGAIS

Priscila Koeller

André Tortato Rauen

Junho de 2021 



\section{№ 82}

\section{Diset}

Diretoria de Estudos e Políticas Setoriais de Inovação e Infraestrutura

\section{Nota \\ Técnica}

PREVISÃO DE ARRECADAÇÃO DE RECURSOS DO FUNDO NACIONAL DE DESENVOLVIMENTO CIENTÍFICO E TECNOLÓGICO (FNDCT) PARA O PERÍODO 2021-2024, SEGUNDO NOVAS DETERMINAÇÕES LEGAIS

Priscila Koeller

André Tortato Rauen 


\section{Governo Federal}

Ministério da Economia

Ministro Paulo Guedes

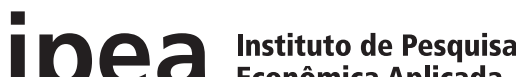 \\ ipea}

Fundação pública vinculada ao Ministério da Economia, o Ipea fornece suporte técnico e institucional às ações governamentais - possibilitando a formulação de inúmeras políticas públicas e programas de desenvolvimento brasileiros - e disponibiliza, para a sociedade, pesquisas e estudos realizados por seus técnicos.

\section{Presidente}

Carlos von Doellinger

Diretor de Desenvolvimento Institucional Manoel Rodrigues Junior

Diretora de Estudos e Políticas do Estado,

das Instituições e da Democracia

Flávia de Holanda Schmidt

\section{Diretor de Estudos e Políticas}

\section{Macroeconômicas}

José Ronaldo de Castro Souza Júnior

Diretor de Estudos e Políticas Regionais,

Urbanas e Ambientais

Nilo Luiz Saccaro Júnior

Diretor de Estudos e Políticas Setoriais de Inovação e Infraestrutura

André Tortato Rauen

Diretora de Estudos e Políticas Sociais

Lenita Maria Turchi

Diretor de Estudos e Relações Econômicas

e Políticas Internacionais

Ivan Tiago Machado Oliveira

Assessor-chefe de Imprensa e Comunicação

André Reis Diniz

Ouvidoria: http://www.ipea.gov.br/ouvidoria

URL: http://www.ipea.gov.br 


\section{№ 82}

\section{Diset}

Diretoria de Estudos e Políticas Setoriais de Inovação e Infraestrutura

\section{Nota \\ Técnica}

PREVISÃO DE ARRECADAÇÃO DE RECURSOS DO FUNDO NACIONAL DE DESENVOLVIMENTO CIENTÍFICO E TECNOLÓGICO (FNDCT) PARA O PERÍODO 2021-2024, SEGUNDO NOVAS DETERMINAÇÕES LEGAIS

Priscila Koeller

André Tortato Rauen

Junho de 2021 


\section{EQUIPE TÉCNICA}

\section{Priscila Koeller}

Analista de planejamento e orçamento na Diretoria de Estudos e Políticas Setoriais de Inovação e Infraestrutura (Diset) do Ipea. E-mail: <priscila. koeller@ipea.gov.br>.

\section{André Tortato Rauen}

Diretor da Diset/lpea.E-mail: <andre.rauen@ipea.gov.br>.

DOI: http://dx.doi.org/10.38116/ntdiset82

As publicações do Ipea estão disponíveis para download gratuito nos formatos PDF (todas) e EPUB (livros e periódicos). Acesse: <http://www.ipea.gov.br/ portal/publicacoes>.

As opiniões emitidas nesta publicação são de exclusiva e inteira responsabilidade dos autores, não exprimindo, necessariamente, o ponto de vista do Instituto de Pesquisa Econômica Aplicada ou do Ministério da Economia.

É permitida a reprodução deste texto e dos dados nele contidos, desde que citada a fonte. Reproduções para fins comerciais são proibidas. 


\section{SUMÁRIO}

1 INTRODUÇÃO. 7 2 EVOLUÇÃO DA ARRECADAÇÃO E DA EXECUÇÃO DO FNDCT... 7 3 LEI COMPLEMENTAR № 177 ...9 4 ESTIMATIVAS DE RECURSOS DO FNDCT .10 5 CONSIDERAÇÕES FINAIS... . .11

REFERÊNCIAS . .12 APÊNDICE A. .13 



\section{INTRODUÇÃO}

O Fundo Nacional de Desenvolvimento Científico e Tecnológico (FNDCT) foi criado em 1969, com o objetivo inicial de garantir recursos para projetos de desenvolvimento científico e tecnológico. A partir do final da década de 1990, com o início da instituição dos fundos setoriais, seu objetivo se amplia e o FNDCT passa também a incorporar o incentivo à inovação. Durante os anos 2000, os fundos setoriais foram se ampliando, tanto em número quanto em recursos, garantindo robustez aos recursos do FNDCT. A importância do fundo para a ciência, tecnologia e inovação (CT\&I) é inegável, tendo em vista que representou, em média, 33\% dos recursos executados pelo governo federal na função ciência e tecnologia no período 2011-2020.

Ao longo dos anos 2000, com o crescimento dos recursos do FNDCT e a necessidade de promover ajustes fiscais conjunturais, foram instituídos mecanismos que inibissem a sua completa utilização, como o direto contingenciamento e a reserva de contingência. Além disso, os recursos não utilizados em um ano, dada a natureza do fundo, não eram revertidos para utilização no ano seguinte. Consequentemente, os recursos não executados se destinavam a melhorar o resultado primário do governo em detrimento do fomento à CT\&I.

Para eliminar essas restrições (contingenciamentos) e garantir que os recursos arrecadados sejam destinados à sua destinação original, em março de 2021 foi aprovada a Lei Complementar no ${ }^{177,{ }^{1}}$ que tem como principal objetivo garantir a estabilidade e continuidade de recursos do FNDCT para o apoio ao desenvolvimento científico e tecnológico e inovação.

A nota pretende, então, analisar a evolução dos recursos do FNDCT, desde a sua criação até 2020, e apresentar estimativas de arrecadação para 2021 e 2022.

\section{EVOLUÇÃO DA ARRECADAÇÃO E DA EXECUÇÃO DO FNDCT}

Os recursos do FNDCT, constituídos por um conjunto de receitas vinculadas, foram crescentes ao longo dos anos. Sua arrecadação está, atualmente, baseada prioritariamente nos recursos dos fundos setoriais. As principais fontes de recursos que compõem essa arrecadação são: Compensações Financeiras pela Exploração de Recursos Minerais; Compensações Financeiras pela Produção de Petróleo, Gás Natural e Outros Hidrocarbonetos Fluidos; Compensações Financeiras pela Utilização de Recursos Hídricos; Cota-Parte do Adicional ao Frete para Renovação da Marinha Mercante; Fundo de Fiscalização das Telecomunicações; Receitas da Contribuição de Intervenção no Domínio Econômico; Percentual do Faturamento Bruto de Empresas que Desenvolvam ou Produzam Bens e Serviços de Informática e Automação; Recursos de Concessões e Permissões (do setor espacial, de empresas de energia elétrica, e infraestrutura rodoviária); e Recursos Financeiros Decorrentes de Aplicações em Programas e Projetos, e Fundos de Investimentos. ${ }^{2}$

O gráfico 1 mostra o crescimento dos recursos do FNDCT como percentagem do produto interno bruto (PIB), para o período 2000-2020. Claro que, nos anos iniciais, o aumento esteve relacionado à criação de novos fundos setoriais com novas fontes vinculadas de recursos. 
GRÁFICO 1

Arrecadação do FNDCT em relação ao PIB (2000-2020)

$(\mathrm{Em} \%)$

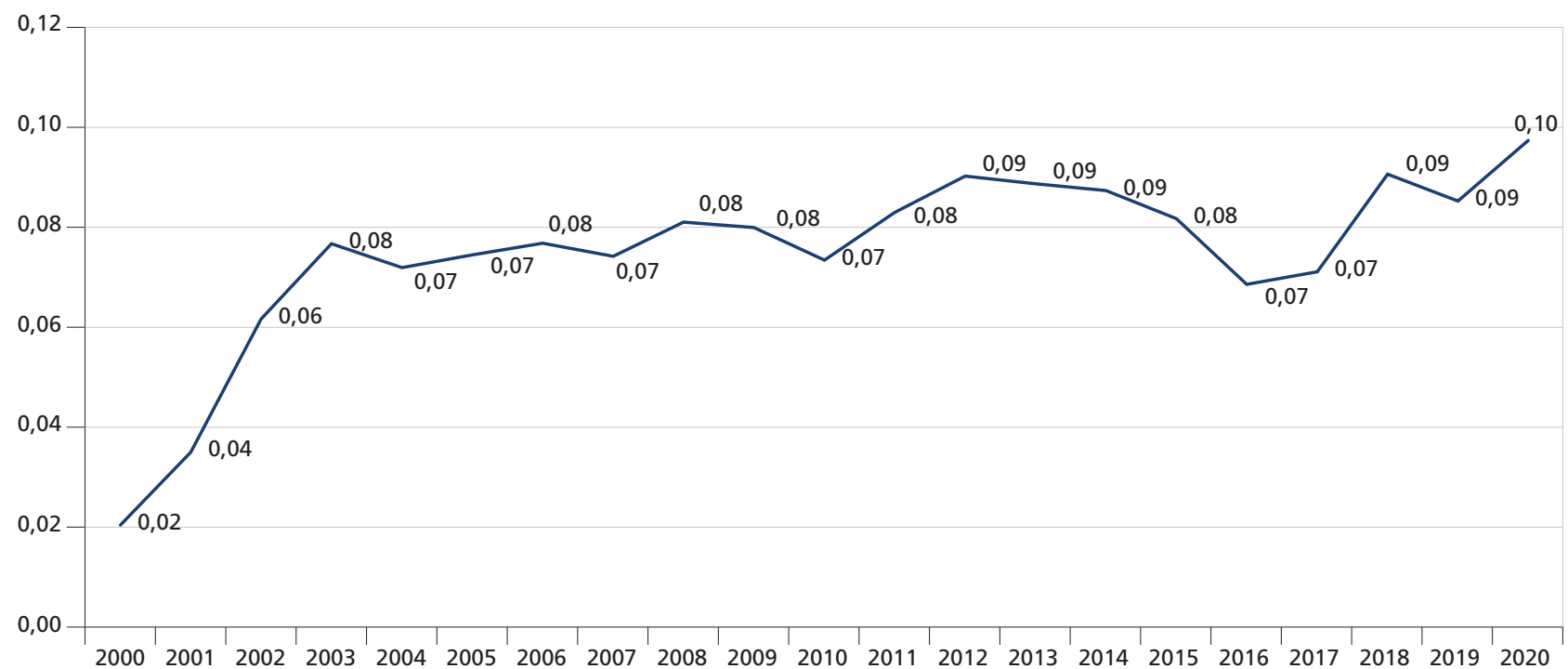

Fontes: Financiadora de Estudos e Projetos (Finep); Tesouro Gerencial; Secretaria do Tesouro Nacional (STN).

A evolução da arrecadação e da execução dos recursos do FNDCT, no entanto, conta histórias distintas, mostrando que a intenção inicial do fundo de garantir recursos para pesquisa, desenvolvimento e inovação (PD\&I) não se concretizou ao longo do caminho. O gráfico 2 mostra que o percentual da arrecadação não executada cresceu significativamente, chegando a $89 \%$ em 2020 .

GRÁFICO 2

Arrecadação não executada (2000-2020)

$($ Em \%)

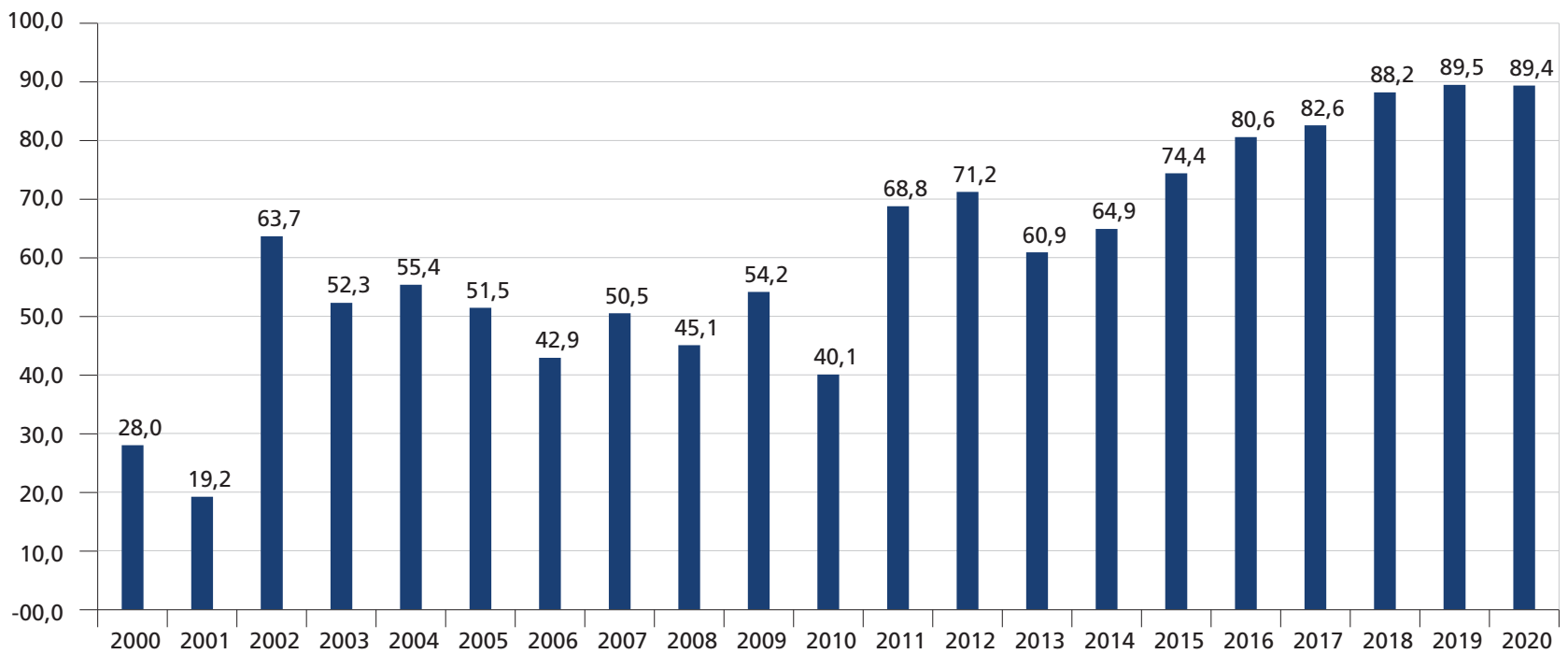

Fontes: Finep; Sistema Integrado de Orçamento e Planejamento (SIOP).

Essa diferença entre arrecadação e execução é explicada principalmente pela instituição de reservas de contingência dos recursos do fundo no Projeto de Lei Orçamentária Anual (PLOA) e, subsequentemente, na Lei Orçamentária Anual (LOA). ${ }^{3} \mathrm{O}$ gráfico 3 apresenta a evolução da reserva de contingência do FNDCT em relação ao total dos recursos do fundo ${ }^{4}$ nesse período, mostrando seu crescimento, especialmente nos últimos anos.

3. Inicialmente, esses recursos eram contingenciados pelos decretos de programação orçamentária e financeira. Para evitar esse contingenciamento, os recursos do FNDCT passaram a ser uma das exceções ao contingenciamento previstas na Lei de Diretrizes Orçamentárias (LDO), ainda nos anos 2000. A partir de então, os limites ao FNDCT passaram a ser impostos pelas reservas de contingência - previstas no Projetos de Lei Orçamentária Anual (PLOA).

4. Foram consideradas as seguintes unidades orçamentárias: 24901 - Fundo Nacional de Desenvolvimento Científico e Tecnológico; 74910 - Re-

cursos sob Supervisão do Fundo Nacional de Desenvolvimento Científico e Tecnológico/FNDCT-M. Ciência, Tecnol. e Inov.; e 93436 - Recursos do Fundo Nacional de Desenvolvimento Científico e Tecnológico (24901). 
GRÁFICO 3

Participação da Reserva de Contingência no total do FNDCT (2000-2021)

(Em \%)

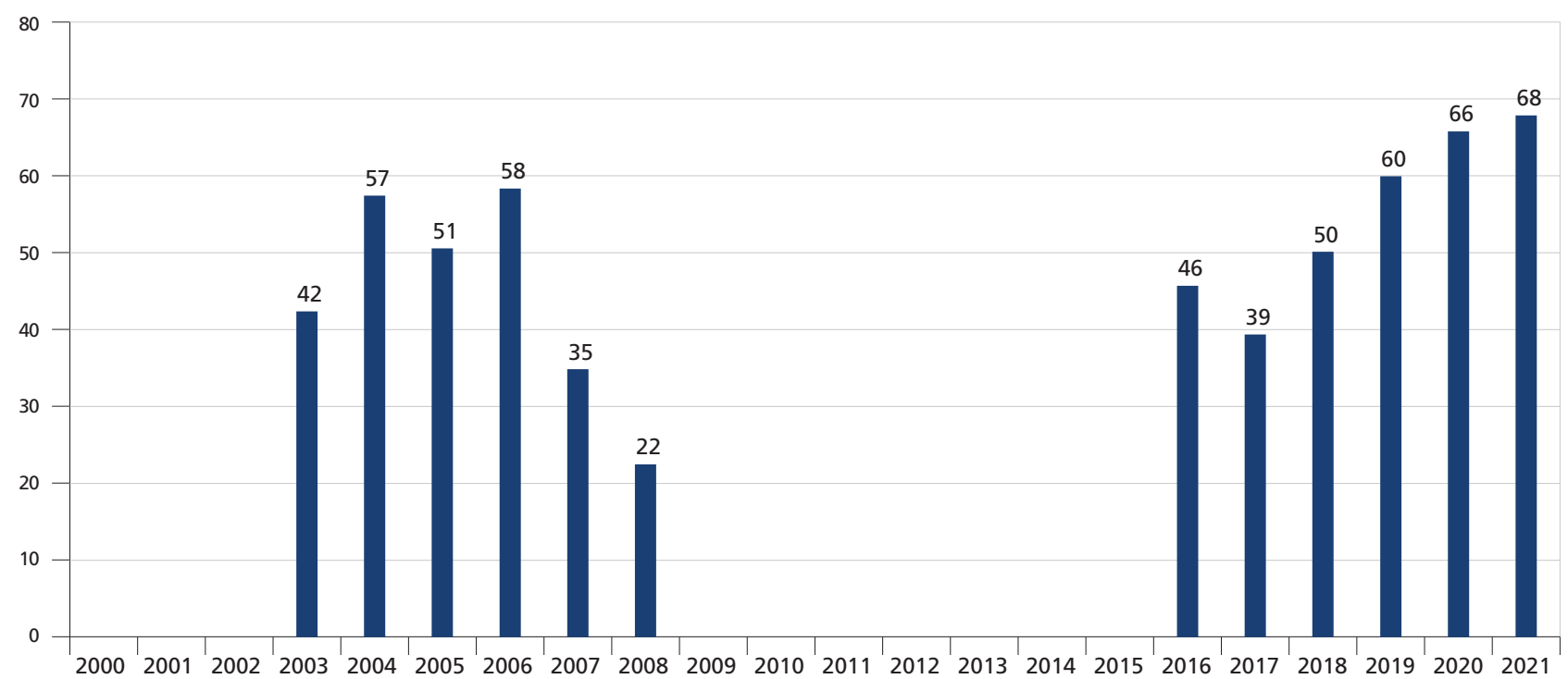

Fontes: Finep; SIOP.

\section{LEI COMPLEMENTAR № 177}

Nesse contexto de restrição de recursos do FNDCT, em 2020 foi proposto o projeto de Lei Complementar (LC) no 135 (PLP 135/2020), ${ }^{5}$ visando garantir a continuidade e estabilidade de recursos para PD\&I no Brasil, aspecto identificado por diversos pesquisadores ${ }^{6}$ como um dos principais problemas para as políticas de CT\&I. Para tanto, o projeto propunha instituir mecanismos que evitassem essas restrições de empenho e movimentação financeira de recursos, tornasse o FNDCT um fundo de natureza contábil e financeira, e garantisse "a reversão dos saldos financeiros anuais não utilizados até o final do exercício, apurados no balanço anual”.

A LC no 177, promulgada em 12 de janeiro de 2021, altera a LCo 1017, de 4 de maio de 2000, que estabelece normas de finanças públicas, e a Lei no 11.540 , de 12 de novembro de $2007 .{ }^{8}$ O quadro 1 sintetiza as principais alterações trazidas pela nova norma, e que protegem os recursos do FNDCT de possíveis contingenciamentos.

\section{QUADRO 1}

Principais alterações introduzidas pela Lei Complementar (LC) no 177

\begin{tabular}{|c|c|c|}
\hline $\begin{array}{c}\text { Legislação } \\
\text { alterada }\end{array}$ & Original & Alteração \\
\hline & \multicolumn{2}{|c|}{$\begin{array}{l}\text { Art. 9. Se verificado, ao final de um bimestre, que a realização da receita poderá não comportar o cumprimento } \\
\text { das metas de resultado primário ou nominal estabelecidas no Anexo de Metas Fiscais, os Poderes e o Ministério } \\
\text { Público promoverão, por ato próprio e nos montantes necessários, nos trinta dias subseqüentes, limitação de } \\
\text { empenho e movimentação financeira, segundo os critérios fixados pela lei de diretrizes orçamentárias. }\end{array}$} \\
\hline $\mathrm{LC} \mathrm{n}^{-} 101$ & $\begin{array}{l}\S 2^{\circ} \text { Não serão objeto de limitação as despesas } \\
\text { que constituam obrigações constitucionais e } \\
\text { legais do ente, inclusive aquelas destinadas ao } \\
\text { pagamento do serviço da dívida, e as ressalva- } \\
\text { das pela Lei de Diretrizes Orçamentárias. }\end{array}$ & $\begin{array}{l}\S 2^{\circ} \text { Não serão objeto de limitação as despesas que constituam } \\
\text { obrigações constitucionais e legais do ente, inclusive aquelas des- } \\
\text { tinadas ao pagamento do serviço da dívida, as relativas à inovação } \\
\text { e ao desenvolvimento científico e tecnológico custeadas por fundo } \\
\text { criado para tal finalidade e as ressalvadas pela Lei de Diretrizes } \\
\text { Orçamentárias (grifo nosso). }\end{array}$ \\
\hline
\end{tabular}

\footnotetext{
5. Disponível em: <https://bit.ly/3xd6JLa>. Acesso em: 13 abr. 2021.

6. Ver, por exemplo, Pacheco (2007) e De Negri e Koeller (2019).

7. Disponível em: <https://bit.ly/2U0DcWN>. Acesso em: 13 abr. 2021

8. Disponível em: <https://bit.ly/3g7Rkpw>. Acesso em: 13 abr. 2021.
} 
Art. 11. Para fins desta Lei, constitui objeto da destinação dos recursos do FNDCT o apoio a programas, projetos e atividades de ciência, tecnologia e inovação (C,T\&I), compreendendo a pesquisa básica ou aplicada, a inovação, a transferência de tecnologia e o desenvolvimento de novas tecnologias de produtos e processos, de bens e de serviços, bem como a capacitação de recursos humanos, o intercâmbio científico e tecnológico e a implementação, manutenção e recuperação de infraestrutura de pesquisa de C,T\&I. ${ }^{9}$

\begin{tabular}{|c|c|c|}
\hline \multirow{3}{*}{ Lei nº 11.540} & - & $\begin{array}{l}\S 1^{\circ} \text { Os créditos orçamentários programados no FNDCT não serão } \\
\text { objeto da limitação de empenho prevista no art. 9o da Lei Comple- } \\
\text { mentar } n^{\circ} \text { 101, de } 4 \text { de maio de } 2000 \text { (grifo nosso). }\end{array}$ \\
\hline & - & $\begin{array}{l}\S 2^{\circ} \text { É vedada a imposição de quaisquer limites à execução da pro- } \\
\text { gramação financeira relativa às fontes vinculadas ao FNDCT, exceto } \\
\text { quando houver frustração na arrecadação das receitas correspon- } \\
\text { dentes (grifo nosso). }\end{array}$ \\
\hline & - & $\begin{array}{l}\S 3 \text { É vedada a alocação orçamentária dos valores provenientes de } \\
\text { fontes vinculadas ao FNDCT em reservas de contingência de nature- } \\
\text { za primária ou financeira (grifo nosso). (Incluído pela Lei Comple- } \\
\text { mentar no } 177 \text {, de 2021) (Parte promulgada pelo Congresso Nacio- } \\
\text { nal) (Promulgação partes vetadas }{ }^{1} \text { ) }\end{array}$ \\
\hline
\end{tabular}

Fontes: Brasil (2000; 2007; 2021).

Nota: ${ }^{1}$ Disponível em: <https://bit.ly/3pH8vRS>.

Destaca-se que a lei promulgada em janeiro teve o parágrafo $3^{\circ}$ do art. 11 vetado pela Presidência da República, justamente aquele relativo à proibição da instituição de reserva de contingência aos recursos dos fundos. Em virtude de intensa mobilização da comunidade acadêmica, ${ }^{10}$ esse parágrafo foi reestabelecido e promulgado em 26 de março de 2021, após a derrubada do veto pelo Congresso Nacional. A redação final reestabelecida está apresentada no quadro $1 .{ }^{11}$

\section{ESTIMATIVAS DE RECURSOS DO FNDCT}

Com a nova lei, o volume de recursos disponíveis para execução tende a crescer significativamente em um primeiro momento, como mostra a tabela 1 . O aumento da execução entre 2021 e 2020, considerando-se que todo o orçamento previsto para 2021 deverá ser executado, será de 203\% (com base no PIB estimado para 2021).

Para o período 2022-2024, foram elaboradas estimativas que permitem avaliar a disponibilidade de recursos. ${ }^{12}$ Para a realização dessas estimativas, foram considerados dois cenários para a arrecadação de 2021:

- no primeiro cenário (A), a arrecadação de 2021 é exatamente igual ao valor estabelecido na LOA 2021;

- para o segundo cenário (B), a arrecadação da LOA é estimada com base na taxa de crescimento (nominal) das receitas líquidas primárias do governo central.

A taxa de crescimento das receitas líquidas primárias do governo central é utilizada para estimar os anos 2022, 2023 e 2024. Os parâmetros empregados para receita líquida primária do governo central e PIB se baseiam na Mensagem da Lei de Diretrizes Orçamentárias de 2022.

9. As alterações introduzidas na redação original não mudam a interpretação. Redação Original: "Art. 11. Para fins desta Lei, constitui objeto da destinação dos recursos do FNDCT o apoio a programas, projetos e atividades de Ciência, Tecnologia e Inovação - C,T\&I, compreendendo a pesquisa básica ou aplicada, a inovação, a transferência de tecnologia e o desenvolvimento de novas tecnologias de produtos e processos, de bens e de serviços, bem como a capacitação de recursos humanos, intercâmbio científico e tecnológico e a implementação, manutenção e recuperação de infraestrutura de pesquisa de C,T\&I”. Disponível em: <https://bit.ly/3xdhdtK> e <https://bit.ly/3xgM6Ob>. Acesso em: 13 abr. 2021.

10. Disponível em: <https://bit.ly/3pRxrqh>. Acesso em: 13 abr. 2021.

11. Disponível em: <https://bit.ly/3xhP2dr>. Acesso em: 13 abr. 2021.

12. As estimativas realizadas não levaram em consideração as novas receitas previstas pelo art. 10 da LC nº 177 em seu inciso XVII. "Art. 10 . Constituem receitas do FNDCT: (...) XVII - a reversão dos saldos financeiros anuais não utilizados até o final do exercício, apurados no balanço anual; " (Brasil, 2021a). Esta opção, por não considerar as novas fontes de receitas nas estimativas, deriva da falta de parâmetros claros para a realização das estimativas. Isto porque tais receitas podem ter sido incorporadas, ao menos parcialmente, em anos anteriores, como sinalizam os incisos I e X, a saber: "I - as dotações consignadas na lei orçamentária anual e seus créditos adicionais"; "X - o produto do rendimento de suas aplicações em programas e projetos, bem como nos fundos de investimentos referidos no § $1^{\circ}$ do art. 12 desta Lei”. Em especial, destaca-se a receita prevista no inciso XVII (reversão dos saldos financeiros anuais não utilizados até o final do exercício), cuja previsão de incorporação ao orçamento existe desde a Lei no 4.320/1964, que prevê, em seu art. 73: "Salvo determinação em contrário da lei que o instituiu, o saldo positivo do fundo especial apurado em balanço será transferido para o exercício seguinte, a crédito do mesmo fundo" (Brasil, 1964), e foi reforçada pelo 
A tabela 1 apresenta as estimativas para arrecadação do FNDCT para o período 2022-2024, segundo os dois cenários considerados.

TABELA 1

Estimativa de arrecadação do FNDCT (2022-2024)

\begin{tabular}{|c|c|c|c|c|c|c|}
\hline Cenários & Anos & $\begin{array}{l}\text { LOA FNDCT } \\
\text { (R\$ correntes) }\end{array}$ & $\begin{array}{l}\text { Arrecadação } \\
\text { FNDCT (R } \$ \text { cor- } \\
\text { rentes) }\end{array}$ & $\begin{array}{c}\text { Execução FNDCT } \\
\text { (R } \$ \text { correntes) }\end{array}$ & $\begin{array}{c}\text { Arrecadação } \\
\text { FNDCT } \\
\text { (\% do PIB })\end{array}$ & $\begin{array}{c}\text { Execução } \\
\text { FNDCT } \\
\text { (\% do PIB) }\end{array}$ \\
\hline \multirow{6}{*}{ A } & 2019 & 5.650 .816 .431 & 6.313.354.563 & 2.076 .573 .534 & 0,09 & 0,03 \\
\hline & 2020 & 6.843 .741 .708 & 7.193 .952 .457 & 2.205 .125 .206 & 0,10 & 0,03 \\
\hline & 2021 & 7.366.211.235 & 7.366 .211 .235 & 7.366.211.235 & 0,09 & 0,09 \\
\hline & 2022 & - & 7.944.080.209 & 7.944.080.209 & 0,09 & 0,09 \\
\hline & 2023 & - & 8.454 .294 .576 & 8.454 .294 .576 & 0,09 & 0,09 \\
\hline & 2024 & - & 9.044 .537 .824 & 9.044 .537 .824 & 0,09 & 0,09 \\
\hline \multirow{6}{*}{ B } & 2019 & 5.650 .816 .431 & 6.313 .354 .563 & 2.076 .573 .534 & 0,09 & 0,03 \\
\hline & 2020 & 6.843.741.708 & 7.193 .952 .457 & 2.205.125.206 & 0,10 & 0,03 \\
\hline & 2021 & 7.366.211.235 & 8.037.117.684 & 7.366.211.235 & 0,10 & 0,09 \\
\hline & 2022 & - & 8.667.618.331 & 8.667.618.331 & 0,10 & 0,10 \\
\hline & 2023 & - & 9.224 .302 .464 & 9.224 .302 .464 & 0,10 & 0,10 \\
\hline & 2024 & - & 9.868 .304 .419 & 9.868 .304 .419 & 0,10 & 0,10 \\
\hline
\end{tabular}

Fontes: STN; Tesouro Gerencial; Mensagem da Lei de Diretrizes Orçamentárias 2022.

Obs.: Para a execução de 2019 e 2020, foram considerados os valores liquidados das respectivas LOAs. Para 2021, considerou-se que todo o orçamento previsto para 2021 será executado.

No cenário A, em que a arrecadação de 2021 coincide com os valores alocados na LOA 2021, e considerando-se que todo o orçamento programado para 2021 será executado, tendo o PIB estimado como parâmetro, não haveria crescimento dos recursos para execução em relação ao orçamento aprovado até 2024, sendo que, para 2022, haveria uma redução de 0,4\% do valor executado em relação ao PIB, em comparação a 2021.

No cenário B, em que a arrecadação de 2021 seria reestimada, permitindo uma nova base para estimação dos anos subsequentes, o crescimento da execução em relação ao PIB já ocorreria em $2022(8,6 \%)^{13}$

Cumpre destacar que o cenário A, em que a arrecadação do FNDCT seria igual àquela prevista pela Lei Orçamentária, é uma hipótese conservadora, levando-se em conta que, em 2019, a arrecadação do fundo foi 11,7\% superior ao valor previsto na LOA, e, em 2020, foi 5,1\% superior. Em contraposição, a estimativa do cenário B para a arrecadação em 2021 poderia ser considerada otimista, pois essa arrecadação seria 9,1\% superior ao valor previsto na Lei Orçamentária.

\section{CONSIDERAÇÕES FINAIS}

O ano de 2021 é, certamente, um dos marcos fundamentais para a continuidade do FNDCT e para a instituição de uma fonte de recursos estável e contínua para CT\&I no país. A partir dessa fonte, e retirados os empecilhos à sua execução, será possível avançar no planejamento para o desenvolvimento do país com base no desenvolvimento científico e tecnológico, e na inovação.

Os efeitos da LC no 177 serão de longo prazo e, já no curto prazo, devem representar um aumento significativo do volume de recursos a serem executados. Esse volume exigirá capacidade de execução do FNDCT, ainda mais levando-se em conta a diferença significativa entre os valores atualmente executados e aqueles que estarão disponíveis a partir de agora.

A análise dos recursos disponíveis para a execução pelo FNDCT nos próximos anos deverá acompanhar também os possíveis impactos da Emenda Constitucional (EC) $\mathrm{n}^{\mathrm{0}}$ 109, de março de 2021, sobre o superavit financeiro do fundo. A EC no 109 prevê, em seu art. 5: "Até o final do segundo exercício financeiro subsequente à data da promulgação desta Emenda Constitucional, o superavit financeiro das fontes de recursos dos fundos públicos do Poder Executivo, apurados ao final de cada exercício, poderá ser destinado à amortização da dívida pública do respectivo ente" (Brasil, 2021b).

13. O valor executado de 2021 será igual ao orçamento aprovado, uma vez que a execução prevista para 2021 tem, necessariamente, que respeitar os valores previstos na LOA 2021. 
Adicionalmente, chama atenção que a própria EC nํㅜ 109 criou exceções à utilização dos fundos públicos, sendo que, entre elas, não está o FNDCT. Contudo, o texto dessa emenda é apenas uma possibilidade, o que, portanto, exige o acompanhamento das decisões gerais no que se refere ao superavit primário.

É importante ressaltar ainda que a maior parte dos recursos do FNDCT é executada via editais e chamadas públicas, o que envolve capacidade de planejamento, execução, acompanhamento e avaliação da Finep, instituição responsável pela Secretaria Executiva do fundo.

Destaca-se ademais que, no próximo ano, a Estratégia Nacional de Ciência, Tecnologia e Inovação (ENCTI) será possivelmente revista, uma vez que 2022 é o último ano da estratégia em vigor. A disponibilidade de recursos de forma contínua e assegurada e as regras definidas para a utilização do FNDCT devem ser consideradas nessa elaboração, abrindo novas perspectivas para a política.

Finalmente, a discussão sobre um novo modelo de governança do FNDCT será fundamental, haja vista o excesso de ações transversais que diminuiu a relevância dos comitês setoriais na alocação efetiva dos recursos, o que acabou por descaracterizar a própria natureza dos fundos que compõem o FNDCT.

\section{REFERÊNCIAS}

BRASIL. Lei no 4.320, de 17 de março de 1964. Estatui Normas Gerais de Direito Financeiro para elaboração e controle dos orçamentos e balanços da União, dos Estados, dos Municípios e do Distrito Federal. Diário Oficial, Brasília, p. 2745, 23 mar. 1964. Disponível em: <https://bit.ly/35lwjlj>. Acesso em: 13 abr. 2021.

Decreto $\mathrm{n}^{\circ}$ 93.872, de 23 de dezembro de 1986. Dispõe sobre a unificação dos recursos de caixa do Tesouro Nacional, atualiza e consolida a legislação pertinente e dá outras providências. Diário Oficial, Brasília, p. 19738, 24 dez. 1986. Disponível em: <https://bit.ly/3czj6cp>.

Lei Complementar ํㅡㄴ 101, de 4 de maio de 2000. Estabelece normas de finanças públicas voltadas para a responsabilidade na gestão fiscal e dá outras providências. Diário Oficial, Brasília, p. 1, 5 maio 2000. Disponível em: <https://bit.ly/3weuHoW>. Acesso em: 13 abr. 2021.

Lei $\mathrm{n}^{\mathrm{o}}$ 11.540, de 12 de novembro de 2007. Dispõe sobre o Fundo Nacional de Desenvolvimento Científico e Tecnológico - FNDCT; altera o Decreto-Lei no 719, de 31 de julho de 1969, e a Lei oㅜ 9.478, de 6 de agosto de 1997; e dá outras providências. Diário Oficial, Brasília, p. 1, 13 nov. 2007. Disponível em: <https://bit.ly/3zffyFX>. Acesso em: 13 abr. 2021.

Lei Complementar no 177, de 12 de janeiro de 2021. Altera a Lei Complementar no 101, de 4 de maio de 2000, para vedar a limitação de empenho e movimentação financeira das despesas relativas à inovação e ao desenvolvimento científico e tecnológico custeadas por fundo criado para tal finalidade, e a Lei n⿳0 11.540, de 12 de novembro de 2007, para modificar a natureza e as fontes de receitas do Fundo Nacional de Desenvolvimento Científico e Tecnológico (FNDCT), e incluir programas desenvolvidos por organizações sociais entre as instituições que podem acessar os recursos do FNDCT. Diário Oficial, Brasília, p. 1, 13 jan. 2021a. Disponível em: <https://bit.ly/3xhP2dr>. Acesso em: 13 abr. 2021.

Emenda Constitucional no 109, de 15 de março de 2021. Altera os arts. 29-A, 37, 49, 84, 163, 165, 167, 168 e 169 da Constituição Federal e os arts. 101 e 109 do Ato das Disposições Constitucionais Transitórias; acrescenta à Constituição Federal os arts. 164-A, 167- A, 167-B, 167-C, 167-D, 167-E, 167-F e 167-G; revoga dispositivos do Ato das Disposições Constitucionais Transitórias e institui regras transitórias sobre redução de benefícios tributários; desvincula parcialmente o superávit financeiro de fundos públicos; e suspende condicionalidades para realização de despesas com concessão de auxílio emergencial residual para enfrentar as consequências sociais e econômicas da pandemia da Covid-19. Diário Oficial, Brasília, p. 4, 16 mar. 2021b. Disponível em: <https://bit.ly/3xbpVbZ>. Acesso em: 13 abr. 2021.

DE NEGRI, F.; KOELLER, P. O declínio do investimento público em ciência e tecnologia: uma análise do orçamento do Ministério da Ciência, Tecnologia, Inovações e Comunicações até o primeiro semestre de 2019. Brasília: Ipea, 2019. (Nota Técnica Diset, n. 48). Disponível em: <https://bit.ly/3zscXbY>.

PACHECO, C. A. Estratégia para fundos setoriais. Revista Brasileira de Inovação, Campinas, v. 6, n. 1, p. 191-223, 2007. Disponível em: <https://bit.ly/3pHvigD>. Acesso em: 26 maio 2021. 
QUADRO A.1

Alterações introduzidas pela Lei Complementar (LC) no 177

\begin{tabular}{|c|c|c|}
\hline $\begin{array}{l}\text { Legislação } \\
\text { alterada }\end{array}$ & Original & Alteração \\
\hline \multirow[b]{2}{*}{$\mathrm{LC} \mathrm{n}^{\mathrm{o}} 101$} & \multicolumn{2}{|c|}{$\begin{array}{l}\text { Art. 9. Se verificado, ao final de um bimestre, que a realização da receita poderá não comportar o cumprimento } \\
\text { das metas de resultado primário ou nominal estabelecidas no Anexo de Metas Fiscais, os Poderes e o Ministério } \\
\text { Público promoverão, por ato próprio e nos montantes necessários, nos trinta dias subsequentes, limitação de } \\
\text { empenho e movimentação financeira, segundo os critérios fixados pela Lei de Diretrizes Orçamentárias. }\end{array}$} \\
\hline & $\begin{array}{l}\S 2^{\circ} \text { Não serão objeto de limitação as des- } \\
\text { pesas que constituam obrigações constitu- } \\
\text { cionais e legais do ente, inclusive aquelas } \\
\text { destinadas ao pagamento do serviço da dí- } \\
\text { vida, e as ressalvadas pela lei de diretrizes } \\
\text { orçamentárias. }\end{array}$ & $\begin{array}{l}\S 2^{\circ} \text { Não serão objeto de limitação as despesas que constituam } \\
\text { obrigações constitucionais e legais do ente, inclusive aquelas } \\
\text { destinadas ao pagamento do serviço da dívida, as relativas à ino- } \\
\text { vação e ao desenvolvimento científico e tecnológico custeadas por } \\
\text { fundo criado para tal finalidade e as ressalvadas pela lei de dire- } \\
\text { trizes orçamentárias (grifo nosso). }\end{array}$ \\
\hline \multirow{11}{*}{ Lei no 11.540} & \multicolumn{2}{|c|}{$\begin{array}{l}\text { Art. 1o O Fundo Nacional de Desenvolvimento Científico e Tecnológico (FNDCT), instituído pelo Decreto-Lei } \\
\mathrm{n}^{\circ} \text { 719, de } 31 \text { de julho de 1969, e restabelecido pela Lei no } 8.172 \text {, de } 18 \text { de janeiro de 1991, é um fundo especial de } \\
\text { natureza contábil e financeira e tem o objetivo de financiar a inovação e o desenvolvimento científico e tecnoló- } \\
\text { gico com vistas a promover o desenvolvimento econômico e social do país (grifo nosso). }{ }^{1}\end{array}$} \\
\hline & - & $\begin{array}{l}\text { Parágrafo único. O FNDCT não se caracteriza como fundo de inves- } \\
\text { timentos e não se vincula ao sistema financeiro e bancário nacional } \\
\text { (grifo nosso). }\end{array}$ \\
\hline & \multicolumn{2}{|l|}{ Art. 10. Constituem receitas do FNDCT: } \\
\hline & $\mathrm{XV}$ - outras que lhe vierem a ser destinadas. & $\begin{array}{l}\mathrm{XV} \text { - os resultados de aplicações financeiras sobre as suas disponi- } \\
\text { bilidades (grifo nosso); }\end{array}$ \\
\hline & - & $\begin{array}{l}X V I \text { - os rendimentos de aplicações em fundos de investimentos e } \\
\text { participação no capital de empresas inovadoras (grifo nosso); }\end{array}$ \\
\hline & - & $\begin{array}{l}\text { XVII - a reversão dos saldos financeiros anuais não utilizados até o } \\
\text { final do exercício, apurados no balanço anual (grifo nosso); e }\end{array}$ \\
\hline & - & XVIII - outras que lhe vierem a ser destinadas. \\
\hline & \multicolumn{2}{|c|}{$\begin{array}{l}\text { Art. 11. Para fins desta Lei, constitui objeto da destinação dos recursos do FNDCT o apoio a programas, pro- } \\
\text { jetos e atividades de Ciência, Tecnologia e Inovação (C,T\&I), compreendendo a pesquisa básica ou aplicada, a } \\
\text { inovação, a transferência de tecnologia e o desenvolvimento de novas tecnologias de produtos e processos, de } \\
\text { bens e de serviços, bem como a capacitação de recursos humanos, o intercâmbio científico e tecnológico e a } \\
\text { implementação, manutenção e recuperação de infraestrutura de pesquisa de C,T\&I. }{ }^{2}\end{array}$} \\
\hline & - & $\begin{array}{l}\S 1^{\circ} \text { Os créditos orçamentários programados no FNDCT não serão } \\
\text { objeto da limitação de empenho prevista no art. } \text { 甲o da Lei Comple- } \\
\text { mentar } n^{\mathrm{o}} 101 \text {, de } 4 \text { de maio de } 2000 \text { (grifo nosso). }\end{array}$ \\
\hline & - & $\begin{array}{l}\S 2^{\circ} \text { É vedada a imposição de quaisquer limites à execução da pro- } \\
\text { gramação financeira relativa às fontes vinculadas ao FNDCT, ex- } \\
\text { ceto quando houver frustração na arrecadação das receitas corres- } \\
\text { pondentes (grifo nosso). }\end{array}$ \\
\hline & - & $\begin{array}{l}\S 3^{\circ} \text { É vedada a alocação orçamentária dos valores provenientes de } \\
\text { fontes vinculadas ao FNDCT em reservas de contingência de natu- } \\
\text { reza primária ou financeira (grifo nosso). (Incluído pela Lei Com- } \\
\text { plementar } \mathrm{n}^{-} \text {177, de 2021) (Parte promulgada pelo Congresso } \\
\text { Nacional) (Promulgação partes vetadas }{ }^{1} \text { ) }\end{array}$ \\
\hline
\end{tabular}

1. Redação original: “Art. 1o O Fundo Nacional de Desenvolvimento Científico e Tecnológico - FNDCT, instituído pelo Decreto-Lei nº 719, de 31 de julho de 1969 , e restabelecido pela Lei no 8.172 , de 18 de janeiro de 1991, é de natureza contábil e tem o objetivo de financiar a inovação e o desenvolvimento científico e tecnológico com vistas em promover o desenvolvimento econômico e social do país".

2. As alterações introduzidas na redação original não mudam a interpretação. Redação original: "Art. 11. Para fins desta Lei, constitui objeto da destinação dos recursos do FNDCT o apoio a programas, projetos e atividades de Ciência, Tecnologia e Inovação - C,T\&I, compreendendo a pesquisa básica ou aplicada, a inovação, a transferência de tecnologia e o desenvolvimento de novas tecnologias de produtos e processos, de bens e de serviços, bem como a capacitação de recursos humanos, intercâmbio científico e tecnológico e a implementação, manutenção e recuperação de infraestrutura de pesquisa de C,T\&I”. 
$\S 4^{\circ}$ A aplicação dos recursos referidos no caput deste artigo contemplará o apoio a programas, projetos e atividades de C,T\&I destinados à neutralização das emissões de gases de efeito estufa do Brasil e à promoção do desenvolvimento do setor de bioeconomia (grifo nosso).

Art. 12. Os recursos do FNDCT referentes às receitas previstas no art. 10 desta Lei poderão ser aplicados nas seguintes modalidades:

I - não reembolsável, para financiamentos de despesas correntes e de capital, na forma do regulamento, para:

Lei $\mathrm{n}^{\mathrm{o}} 11.540$

d) programas desenvolvidos por organizações sociais, qualificadas conforme a Lei $n^{0}$ 9.637, de 15 de maio de 1998, que mantenham contrato de gestão com o Ministério da Ciência, Tecnologia e Inovações e que promovam e incentivem a realização de projetos de pesquisa, desenvolvimento e inovação, limitado a $25 \%$ (vinte e cinco por cento) dos recursos disponibilizados no FNDCT para operações não reembolsáveis, a cada exercício (grifo nosso);

II - reembolsável, destinados a projetos de desenvolvimento tecnológico de empresas, sob a forma de empréstimo à Finep, que assume o risco integral da operação, observados, cumulativamente, os seguintes limites:

a) o montante anual das operações não poderá ultrapassar $25 \%$ (vinte e cinco por cento) das dotações consignadas na lei orçamentária anual ao FNDCT;

a) o montante anual das operações não poderá ultrapassar $50 \%$ (cinquenta por cento) das dotações consignadas na lei orçamentária anual ao FNDCT (grifo nosso);

Art. 14. Os recursos do FNDCT poderão financiar as ações transversais, identificadas com as diretrizes da Política Nacional de Ciência, Tecnologia e Inovação e com as prioridades da Política Industrial e Tecnológica Nacional. $\S 4^{\circ}$ Os recursos do FNDCT passíveis de financiar as ações transversais são aqueles oriundos das receitas previstas nos incisos I a VI, VIII e X a XV do caput do art. 10 desta Lei.

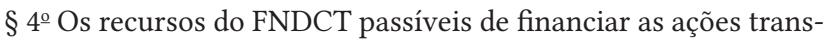
versais são aqueles oriundos das receitas previstas nos incisos I a VI, VIII e X a XVIII do caput do art. 10 desta Lei (grifo nosso).

Fontes: Brasil (2000; 2007; 2021).

Elaboração dos autores.

Nota: ${ }^{1}$ Disponível em: <https://bit.ly/3pH8vRS>.

\section{REFERÊNCIAS}

BRASIL. Lei Complementar n⿳ำ 101, de 4 de maio de 2000. Estabelece normas de finanças públicas voltadas para a responsabilidade na gestão fiscal e dá outras providências. Diário Oficial, Brasília, p. 1, 5 maio 2000. Disponível em: <https://bit.ly/3weuHoW>. Acesso em: 13 abr. 2021.

Lei no 11.540 , de 12 de novembro de 2007. Dispõe sobre o Fundo Nacional de Desenvolvimento Científico e Tecnológico - FNDCT; altera o Decreto-Lei no 719, de 31 de julho de 1969, e a Lei no 9.478, de 6 de agosto de 1997; e dá outras providências. Diário Oficial, Brasília, p. 1, 13 nov. 2007. Disponível em: <https://bit.ly/3zffyFX>. Acesso em: 13 abr. 2021.

. Lei Complementar no 177, de 12 de janeiro de 2021. Altera a Lei Complementar no 101, de 4 de maio de 2000 , para vedar a limitação de empenho e movimentação financeira das despesas relativas à inovação e ao desenvolvimento científico e tecnológico custeadas por fundo criado para tal finalidade, e a Lei 꾸 11.540 , de 12 de novembro de 2007, para modificar a natureza e as fontes de receitas do Fundo Nacional de Desenvolvimento Científico e Tecnológico (FNDCT), e incluir programas desenvolvidos por organizações sociais entre as instituições que podem acessar os recursos do FNDCT. Diário Oficial, Brasília, p. 1, 13 jan. 2021. Disponível em: <https://bit.ly/3xhP2dr>. Acesso em: 13 abr. 2021. 

Ipea - Instituto de Pesquisa Econômica Aplicada

\section{EDITORIAL}

\section{Chefe do Editorial}

Reginaldo da Silva Domingos

\section{Assistentes da Chefia}

Rafael Augusto Ferreira Cardoso

Samuel Elias de Souza

\section{Supervisão}

Camilla de Miranda Mariath Gomes

Everson da Silva Moura

\section{Editoração}

Aeromilson Trajano de Mesquita

Anderson Silva Reis

Cristiano Ferreira de Araújo

Danilo Leite de Macedo Tavares

Jeovah Herculano Szervinsk Junior

Leonardo Hideki Higa

\section{Capa}

Danielle de Oliveira Ayres

Flaviane Dias de Sant'ana

The manuscripts in languages other than Portuguese published herein have not been proofread.

\section{Livraria Ipea}

SBS - Quadra 1 - Bloco J - Ed. BNDES, Térreo

70076-900 - Brasília - DF

Tel.: (61) 2026-5336

Correio eletrônico: livraria@ipea.gov.br 

Composto em linux libertine 10/13 (texto) 



\section{Missão do Ipea}

Aprimorar as políticas públicas essenciais ao desenvolvimento brasileiro por meio da produção e disseminação de conhecimentos e da assessoria ao Estado nas suas decisões estratégicas.

\section{ipea Econômica Aplicada}

